\title{
Sexually transmitted diseases in South Africa
}

\author{
G B T Pham-Kanter, M H Steinberg, R C Ballard
}

\begin{abstract}
Aim: To review the epidemiology of and data collection for sexually transmitted diseases (STDs) in South Africa.

Methods: Literature published since 1980 on STDs in South Africa were compiled and evaluated. Historical reports and salient unpublished literature were also used in the literature review. Studies were critically reviewed in the light of sample populations and study methods, and a baseline picture of the patterns of STD burden was developed.

Results: The STD burden in apparently asymptomatic study populations is significant. Ulcerative infections, primarily caused by syphilis and chancroid, are present in $5-15 \%$ of asymptomatic clinic attenders; prevalence rates of gonorrhoea average $8 \%$, with up to $13 \%$ of gonococcal isolates resistant to penicillin antibiotics. In addition, on average, chlamydia and vaginal infections are detected in $16 \%$ and $20-49 \%$, respectively, of antenatal and family planning clinic attenders. HIV seroprevalence rates have reached $7.6 \%$ in antenatal clinic attenders. Most South African STD data are derived from ad hoc surveys which have traditionally focused only on several major infections and particular urban centres. Almost all STD studies have been facilitybased, with many studies based at STD clinics, thus reporting only relative frequencies and not population-based prevalences of STDs. With the possible exception of HIV, systematic surveillance data for STDs are conspicuously lacking.

Conclusion: The disease burden of classic sexually transmitted infections has historically been heavy, and continues to be a serious public health problem in South Africa. Morbidity from both ulcerative and non-ulcerative infections, particularly in women, is significant. The body of STD data, although mostly sound, remains incomplete, and with the rapid emergence of HIV in South Africa, surveillance of STDs and focused STD policies will be critical. (Genitourin Med 1996;72:160-171)
\end{abstract}

Keywords: STD; South Africa; epidemiology

\section{Introduction}

With the appearance of HIV/AIDS, sexually transmitted diseases (STDs) have re-emerged as a grave public health problem, particularly in developing countries. There is strong evidence showing that the presence of genital ulcer disease and of some non-ulcerative STDs enhances the transmission of HIV. ${ }^{1-3}$ In addition, the presence of HIV is known to alter the presentation and clinical course of STDs, and to increase the frequency of treatment failure for some sexually transmitted infections. ${ }^{1}$ The inter-relationships between HIV and STDs mean that an understanding of the burden and transmission patterns of STDs is imperative if the control of both STDs and HIV is to be pursued in an informed manner.

In South Africa, the epidemiology of STDs has been largely neglected. The historical lack of interest in STDs as a health priority, the absence of a surveillance system which encompasses STDs, and the difficulties of collecting data from a fragmented health care system have resulted in a dearth of reliable STD data. Facility-based ad hoc surveys have provided some point estimates of the burden of particular STDs, but a broad cohesive picture of the state of STDs in South Africa is missing.

This review, encompassing STD literature since 1980 , presents a contemporary examination of STDs in South Africa. The epidemiology of the most prevalent STDs is reviewed and the STD burden of the popula- tion is re-examined. The review also provides a close look at the state of STD data in South Africa.

\section{Methods}

Refereed literature published since 1980 on epidemiological aspects of STDs in South Africa were collected. Historical reports, unrefereed published literature, and unpublished literature such as official statistics, working papers, and conference proceedings, were also compiled. Studies were then critically reviewed on the basis of their broader relevance and study methods. Methodological issues evaluated included the size, significance, and representativeness of the sample populations, diagnostic criteria, clinical and laboratory methods used for diagnosis, and techniques of data analysis.

Published studies were included if the reported study methods met the listed methodological criteria; unpublished studies, however, were included only if they met the methodological criteria and if they represented significant developments which had not been published. In a few cases, weaker and less widely applicable studies were noted if they represented the only data set available for a particular infection. In these cases, deficiencies in the studies and related caveats were made explicit. Selected case reports and historical reports were included to provide background context. 


\section{Ulcerative infections}

Syphilis

Prior to the arrival of Europeans, venereal syphilis was apparently unknown in southern Africa. In fact, reports from the first European travellers to the region in the early 1800 s specifically noted the absence of syphilis among the Xhosa and the Bechuana. ${ }^{4}$ By 1887 , however, with the development of the Kimberley diamond mines, syphilis had spread widely within the indigenous population, and Wassermann seroprevalence rates of higher than $80 \%$ were reported in some areas. ${ }^{4}$ A 1949 review by Sidney Kark noted that syphilis seropositivity rates in expectant mothers ranged between $20 \%$ and $40 \%$; not surprisingly, Kark remarked that "few countries can have a higher incidence ... than has South Africa". ${ }^{5}$

Most of current South African syphilis data are serologically-based; thus, some caveats of syphilis serology should be borne in mind when examining this set of data. The main issues in syphilis serology particularly relevant to these data are: (1) nontreponemal reagin tests (rapid plasma reagin or VDRL) are sensitive, becoming negative after successful treatment of early infection, but remaining positive in cases of successful treatment of later stages of syphilis; (2) treponemal tests (fluorescent treponemal antibody absorption or Treponema pallidum haemagglutination) are more sensitive than reagin tests, but remain positive even after successful treatment; (3) the combination of a screening reagin test followed by a confirmatory treponemal test is generally accepted as a standard criterion for syphilis; (4) diagnosis of active syphilis based on either a reagin test alone or a treponemal test alone results in overestimation of true syphilis cases,

Table 1 Percentage seropositivity of syphilis in general population groups

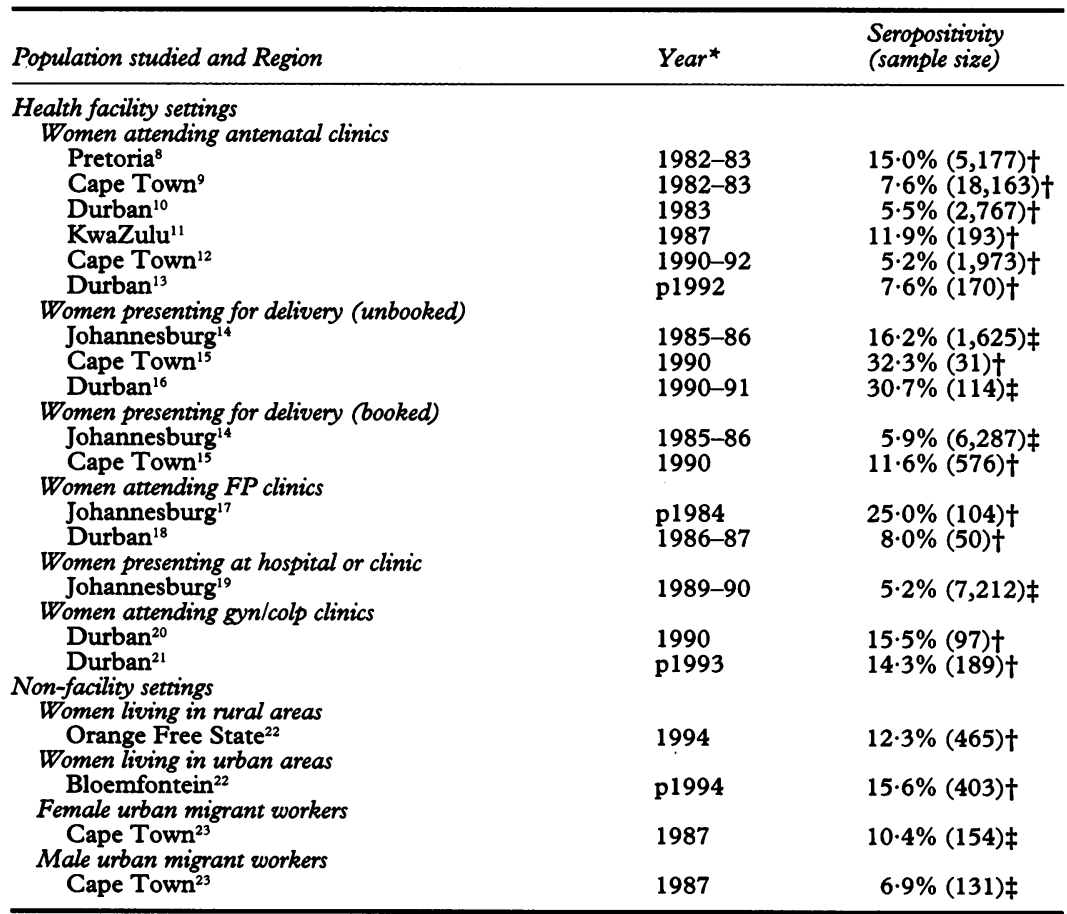

¿Date of survey or, if no survey date available, date of publication (p).

tSeropositivity based on positive reagin test confirmed with positive treponemal test.

†Seropositivity based on positive reagin test

FP: family planning; gyn/colp: gynaecology or colposcopy. but in high prevalence regions such as South Africa, the proportion of false positive reagin tests relative to actual active syphilis cases is small enough that diagnosis based on a reagin test alone may be sufficient. ${ }^{67}$ For these reasons, the studies discussed are limited to those that used, as a diagnostic criterion for syphilis, either a positive reagin test or a positive reagin test confirmed with a positive treponemal test.

Syphilis in general population groups Most study estimates of syphilis seropositivity in general population groups, or more specifically, non-symptomatic groups, were gathered from health facility data. As shown in table 1, 16 of the 20 estimates were based on sample populations of hospital or clinic attenders. Rates among antenatal clinic attenders were typical of facility-based seropositivity rates in most other groups of women studied, with rates ranging from $5.2 \%$ to $15.0 \%$ (median $7 \cdot 6 \%)^{8-13}$

Other groups of women, however, were found to have generally higher rates of seropositivity. One of these groups was the group of "unbooked" pregnant women-that is, women who had either not received antenatal care prior to delivery or had not attended an antenatal clinic a sufficient number of times (usually twice) to be notified of their syphilis status. Seroprevalence of "unbooked" women was reported to be $30.7 \%$ in Durban, $32.3 \%$ in Cape Town, and $16.2 \%$ in Johannesburg. ${ }^{14-16}$ The Johannesburg study also confirmed that the difference in seropositivity rates between "booked" women, with seroprevalence of $5.9 \%$, and "unbooked" pregnant women was significant. ${ }^{14}$

Unpublished studies of "unbooked" women have noted that these women generally tend to be single and unemployed, and have a poor relationship with the father of the child..$^{24-26}$ The major reasons given for not seeking antenatal care are lack of money (or that the clinic is too expensive) and distance from the clinic. ${ }^{24} 25$ In addition, there is speculation that "unbooked" women may be less knowledgeable about the importance of antenatal care ${ }^{25}$ or may have a more carefree attitude towards certain unhealthy behaviours affecting the fetus such as smoking and STDs. ${ }^{26}$ Syphilis seropositivity status may thus be related to such as factors as access to information regarding the importance of antenatal care and STD treatment, and physical and financial access to clinics.

A second group of women with higher seropositivity rates were gynaecology/ colposcopy clinic attenders. ${ }^{2021}$ These women either presented with a gynaecological complaint or, in the case of colposcopy clinic attenders, were referred for gynaecological anomalies, some of which may have been related to the presence of STDs. Thus, they would have been more likely than other clinicattending populations to have tested positive for syphilis.

Notably, rates among women surveyed in non-facility settings also clustered around the high end of the range. ${ }^{22} 23$ These women were 
usually surveyed at their residences (homes or worker hostels), and data from these population samples are believed to be a realistic indication of general population seroprevalence. In comparison with rates from facility data, the generally higher seropositivity rates of these women suggest that facility-based data may often underestimate population seroprevalence. Some non-facility studies may, moreover, be a slight underestimate themselves. In particular, the migrant worker study may have been subject to a "healthy worker" effect in that migrant workers may represent a healthier range of individuals within the broader population.

Syphilis among persons with STDs Data collected at STD clinic sites are theoretically more accurate than those collected at antenatal or family planning (FP) clinics because diagnosis of syphilis in symptomatic patients can rely on clinical signs and dark field microscopy in addition to serology. Despite this advantage, however, studies often rely either on dark field microscopy or on serology-not on both. Another serious drawback of the STD clinic data is that reported prevalence at these sites reflects only relative prevalence, not true population prevalence.

Diagnosis of syphilis, based on either serology or dark field microscopy, is relatively common among men and women presenting with STDs, as shown in table 2. Among men with genital ulcer disease (GUD), the proportion of clients diagnosed with syphilis ranged from $16 \cdot 7 \%$ to $49 \cdot 0 \% .^{27-31}$ This range is extremely wide, but part of the variation in estimates may be due to the choice of diagnostic criteria: whereas serological diagnoses are believed to overestimate the proportion of active syphilis cases, dark field microscopy, depending on the technical proficiency and experience of the microscopist, is believed to underestimate the number of active cases. The "true" proportion of active syphilis cases is believed to be between the serological and dark field-positive values. Indeed, recent results from a study of patients with GUD in Lesotho, a neighbouring southern African country, appear to sup-

Table 2 Syphilis in population groups with STDs

\begin{tabular}{lll}
\hline $\begin{array}{l}\text { Population studied } \\
\text { and Region }\end{array}$ & Year $^{*}$ & $\begin{array}{l}\text { \% Diagnosed } \\
\text { (sample size) }\end{array}$ \\
\hline $\begin{array}{lll}\text { Men with GUD } \\
\quad \text { Johannesburg }\end{array}$ & p1981 & $16 \cdot 7 \%(102) \dagger$ \\
$\quad$ Pretoria $^{28}$ & 1981 & $49 \cdot 0 \%(100) \dagger$ \\
$\quad$ Durban $^{29}$ & 1984 & $44 \cdot 0 \%(100) \dagger$ \\
$\quad \begin{array}{l}\text { Carletonville } \\
\text { Durban }\end{array}$ & 1986 & $25 \cdot 8 \%(240) \dagger$ \\
$\begin{array}{l}\text { Women with GUD } \\
\text { Johannesburg }\end{array}$ & $1988-89$ & $42 \cdot 0 \%(100) \ddagger$ \\
$\begin{array}{c}\text { Durban } \\
\text { Women with PID }\end{array}$ & p1984 & $43 \cdot 0 \%(100) \dagger$ \\
$\quad \begin{array}{l}\text { Durban } \\
\text { Women attending STD clinics } \\
\text { Johannesburg }\end{array}$ & $1988-89$ & $40 \cdot 0 \%(100) \ddagger$ \\
\hline
\end{tabular}

$\star$ Date of survey or, if no survey date available, date of publica-

tion (p). test confirmed with positive treponemal test.

$\ddagger D$ iagnosis based on dark field identification or positive treponemal test.

§Diagnosis based on positive reagin test confirmed with positive treponemal test.

GUD: genital ulcer disease; PID: pelvic inflammatory disease; STD: sexually transmitted disease. port this assertion. The Lesotho study compared the number of syphilis diagnoses based on serology, dark field identification, and polymerase chain reaction (PCR), and showed that, whereas PCR identified syphilis infection in $19 \%$ of cases, dark field identification identified $0 \%$ and serology identified $26 \%$ (unpublished observations).

All the studies reviewed indicated that syphilis was a frequently-diagnosed infection in both men and women with GUD: syphilis was either the single most common infection, or the second most common infection after chancroid. Mixed infections were also frequent when positive syphilis serology was used as the primary diagnostic criterion. About $30 \%$ of GUD patients who had been diagnosed with syphilis harboured other pathogens, with chancroid and genital herpes being the most frequent accompanying infections. In addition, in a broad study of mixed infections, Sischy et al reported that $23 \%$ of clinic patients presenting with non-syphilitic GUD were syphilis seropositive, while $11 \%$ of urethritis patients tested positive for syphilis. ${ }^{34}$

Congenital syphilis In South Africa, estimates of congenital syphilis prevalence rates have been variable, from $0.05 \%$ of live births, based on clinical diagnosis, to $8 \%$ of deliveries, based on RPR of cord blood. ${ }^{14}{ }^{35-37}$ There is no dispute, however, that congenital syphilis remains a leading factor in perinatal mortality in South Africa. One study estimated that 3.2 perinatal deaths per 1000 live births were syphilis-related..$^{38}$ In addition, between $2 \cdot 8 \%$ and $11 \%$ of stillbirths and perinatal deaths have been attributed to syphilis. ${ }^{39-44}$ Although syphilis-related stillbirths are less frequent for mothers who seek antenatal care, ${ }^{42}$ there is some unpublished evidence suggesting that, even among those who sought antenatal care, at least one-third of women were not tested for syphilis; moreover, among those who were tested for syphilis, a significant proportion were inadequately treated and as a result, lost their infants to syphilis-related deaths. ${ }^{37} 4345$

In South Africa, congenital syphilis became a condition notifiable to the Department of National Health and Population Development in February 1991.46 The notification statistics, however, have not been very reliable, with 994 cases notified in 1993 and 910 cases notified in 1994 (unpublished observations). Given the prevalence studies, these notifications clearly represent significant under-reporting of the disease.

\section{Chancroid}

Chancroid poses two particular difficulties with respect to diagnosis and treatment. Although the development of selective solid media for the culture of Haemophilus ducreyi has permitted a high degree of diagnostic accuracy on a microbiological level, accurate clinical diagnosis of chancroid is difficult. Chancroid often presents atypically, and without laboratory confirmation, is often misdiagnosed as syphilis, lymphogranuloma venereum, or genital herpes. ${ }^{47} 48$ The treatment 
of chancroid is also problematic because of the antibiotic resistance exhibited by local isolates of $H$ ducreyi.

Chancroid among persons with STDs Despite the documented importance of chancroid in Africa, only a handful of studies have reported on the scope of chancroid in South Africa. Studies since 1980 reporting on the relative prevalence of chancroid in persons with GUD are shown in table 3. These studies show that chancroid is a leading infection in men with GUD, with $H$ ducreyi being isolated in $40.0 \%$ to $68 \cdot 3 \%$ of cases. ${ }^{27-30}$

Two studies, however, reported extremely low relative frequencies of chancroid among men and women with GUD. ${ }^{3133}$ Although there are slight epidemiological differences between Durban (where these joint studies were conducted) and the other areas surveyed, it is believed that the reasons for the discrepancy in rates are largely due to the particular study populations and laboratory methods used to identify chancroid. First, the Durban study populations may have included fewer prostitutes and their clients, a group believed to be a reservoir for chancroid ${ }^{49}$; as a result, one would expect the Durban study to report a low relative prevalence of chancroid while reporting a high relative prevalence of other STDs. In addition, laboratory methods used to diagnose chancroid in the 1988-89 Durban studies were slightly different from those used in the other studies; although the different methods are accepted laboratory techniques, the varying methodologies may mean that the reported values may not be directly comparable. Both of these factors may explain the low relative frequency of chancroid reported in these studies and may also explain the significant difference between the low $22 \%$ relative frequency reported in the male GUD study and the $40.0 \%$ rate reported for the same region in a study 4 years previously. ${ }^{29}$

Overall, the generally high relative frequency of chancroid in the studies suggest that chancroid is, along with syphilis, a leading infection in persons with GUD. In fact, two of the five GUD studies of men reported chancroid as the single leading infection, ${ }^{27}{ }^{30}$ while the other three reported chancroid as the second leading infection after serologically-diagnosed syphilis. ${ }^{28} 2931$ These studies indicate chancroid and syphilis are leading causes of

Table 3 Chancroid in population groups with STDs

\begin{tabular}{|c|c|c|}
\hline $\begin{array}{l}\text { Population studied } \\
\text { and Region }\end{array}$ & Yeart & $\begin{array}{l}\text { \% Diagnosed } \\
\text { (sample size) }\end{array}$ \\
\hline \multicolumn{3}{|l|}{ Men with GUD } \\
\hline Johannesburg ${ }^{27}$ & p1981 & $56.9 \%(102)$ \\
\hline Pretoria $^{28}$ & 1981 & $44.0 \%(100)$ \\
\hline Durban $^{29}$ & 1984 & $40.0 \%(100)$ \\
\hline Carletonville $^{30}$ & 1986 & $68 \cdot 3 \%(240)$ \\
\hline Durban $^{31}$ & $1988-89$ & $22.0 \%(100)$ \\
\hline \multicolumn{3}{|l|}{ Women with GUD } \\
\hline Johannesburg ${ }^{32}$ & p1984 & $46 \cdot 0 \%(100)$ \\
\hline Durban $^{33}$ & $1988-89$ & $14.0 \%(100)$ \\
\hline
\end{tabular}

$\star$ Diagnosis based on isolation of $H$ ducreyi from lesions. tDate of survey or, if no survey date available, date of publica-

GUD: genital ulcer disease.
GUD in South Africa, representing 70\%-90\% of cases of GUD.

Antimicrobial susceptibilities of $H$ ducreyi The problem of chancroid is compounded by the decreasing susceptibility of $H$ ducreyi to a spectrum of antibiotics. Since the early 1980s, antimicrobial susceptibilities of $H$ ducreyi strains in South Africa have been monitored. In $1982,93 \%$ of isolates produced $\beta$-lactamase, but by $1988,100 \%$ of the 122 tested isolates were shown to produce $\beta$-lactamase. ${ }^{50} 51$ In addition, isolates were shown to be resistant to tetracycline, doxycycline, and sulfamethoxazole, and exhibited intermediate resistance to chloramphenicol and thiamphenicol.

\section{Granuloma inguinale}

Granuloma inguinale, or donovanosis, may well be the first disease to have "disappeared" only to reappear fifty years later. First reported in South Africa by Ricono in $1916,{ }^{52}$ donovanosis appeared sporadically in case reports until the late 1920s; between 1927 and 1981, no cases of donovanosis in South Africa were reported. Freinkel speculates that the unusual half-century "disappearance" of granuloma inguinale may have been due to a change in parasite virulence, regional migration to neighbouring countries, or mis-diagnosis, but concedes that none of these explanations is entirely satisfactory in explaining the apparent disappearance. ${ }^{53}$ The first published re-emergence of granuloma inguinale was in 1981 in a study of men presenting with GUD when one case seen in Johannesburg was clinically and microscopically identified as donovanosis. ${ }^{27}$ Since then, case reports from Durban, the Eastern Transvaal, and the Orange Free State have proliferated. ${ }^{54-58}$

Granuloma inguinale among persons with STDs Granuloma inguinale appears to cause only a small proportion of genital ulcers seen at STD clinics. The five estimates from the Transvaal region indicate that Calymmatobacterium granulomatis is responsible for $<1 \%$ to $2 \%$ of GUD cases. ${ }^{27} 283032$

Studies from Durban, however, are conspicuous for the reporting of relatively high donovanosis rates of $11 \%$ and $16 \%$ among persons with GUD. When adjusted for single infections only, relative prevalence rates of $9 \%$ and $10 \%$ for males and females, respectively, still remain surprisingly high. ${ }^{3133}$ Although KwaZulu-Natal may be one of the few focal centres of granuloma inguinale in the world, the high relative frequency of granuloma inguinale reported from these studies may be at least partially related to the low relative frequency of chancroid noted in the same studies. As discussed in the previous section, the particular study population and methods of isolation for $H$ ducreyi may have resulted in a disproportionately low relative frequency of chancroid and high relative frequency of granuloma inguinale and other STDs.

\section{Lymphogranuloma venereum}

Lymphogranuloma venereum (LGV) appears 
Table 4 Genital herpes infections

\begin{tabular}{|c|c|c|}
\hline Population studied and Region & Yeart & $\begin{array}{l}\text { \% Diagnosed } \\
\text { (sample size) }\end{array}$ \\
\hline $\begin{array}{l}\text { Men with GUD } \\
\text { Johannesburg } \\
\text { Pretoria }^{28} \\
\text { Durban }^{29} \\
\text { Carletonville }^{30} \\
\text { Durban }^{31}\end{array}$ & $\begin{array}{l}\text { p1981 } \\
1981 \\
1984 \\
1986 \\
1988-89\end{array}$ & $\begin{array}{r}8.8 \%(102) \\
5.0 \%(100) \\
9.0 \%(100) \\
3.3 \%(240) \\
10.0 \%(100)\end{array}$ \\
\hline $\begin{array}{l}\text { Women with GUD } \\
\text { Johannesburg } \\
\text { Durban }^{33}\end{array}$ & $\begin{array}{l}\text { p1984 } \\
1988-89\end{array}$ & $\begin{array}{r}6.0 \%(100) \\
18.0 \%(100)\end{array}$ \\
\hline $\begin{array}{l}\text { Women attending STD clinics } \\
\text { Johannesburg }{ }^{17}\end{array}$ & p1984 & $1 \cdot 8 \%(164)$ \\
\hline $\begin{array}{l}\text { Johannesburg } \\
\text { Durban }^{21}\end{array}$ & $\begin{array}{l}1986-87 \\
\text { p1993 }\end{array}$ & $\begin{array}{l}6 \cdot 0 \%(100) \\
2 \cdot 5 \%(199)\end{array}$ \\
\hline $\begin{array}{l}\text { Women attending FP clinics } \\
\text { Johannesburg }{ }^{17}\end{array}$ & p1984 & $1.0 \%(104)$ \\
\hline
\end{tabular}

*Diagnosis based on cytopathic activity in susceptible cells. tDate of survey, or if no survey date available, date of publication $(\mathrm{p})$.

GUD: genital ulcer disease; STD: sexually transmitted disGUD: genital ulcer disease; STD: sexually transmitted dis-
ease; gyn/colp: gynaecology or colposcopy; FP: family planning.

to be a minor contributor to GUD in South Africa, although it is known to be common in some distinct rural regions of the sub-continent, namely the Eastern Transvaal, Natal, and Transkei. LGV is a relatively minor cause of GUD in the major city centres surveyed, with isolation rates around $1 \% .{ }^{27-2931}$ In the mining town of Carletonville, however, isolation rates are considerably higher: $7 \% .{ }^{30}$ This trend is consistent with the fact that many of the miners surveyed are migrant workers who may have acquired their infections from surrounding regions of Lesotho, Botswana, Swaziland, the Eastern Transvaal, and Transkei-areas with higher prevalence of LGV. Notably, although all three L-serovars of Chlamydia trachomatis known to cause LGV have been detected in South Africa, some apparently recombinant chlamydial strains have also recently been isolated..$^{59}$

Table 5 Gonococcal infections

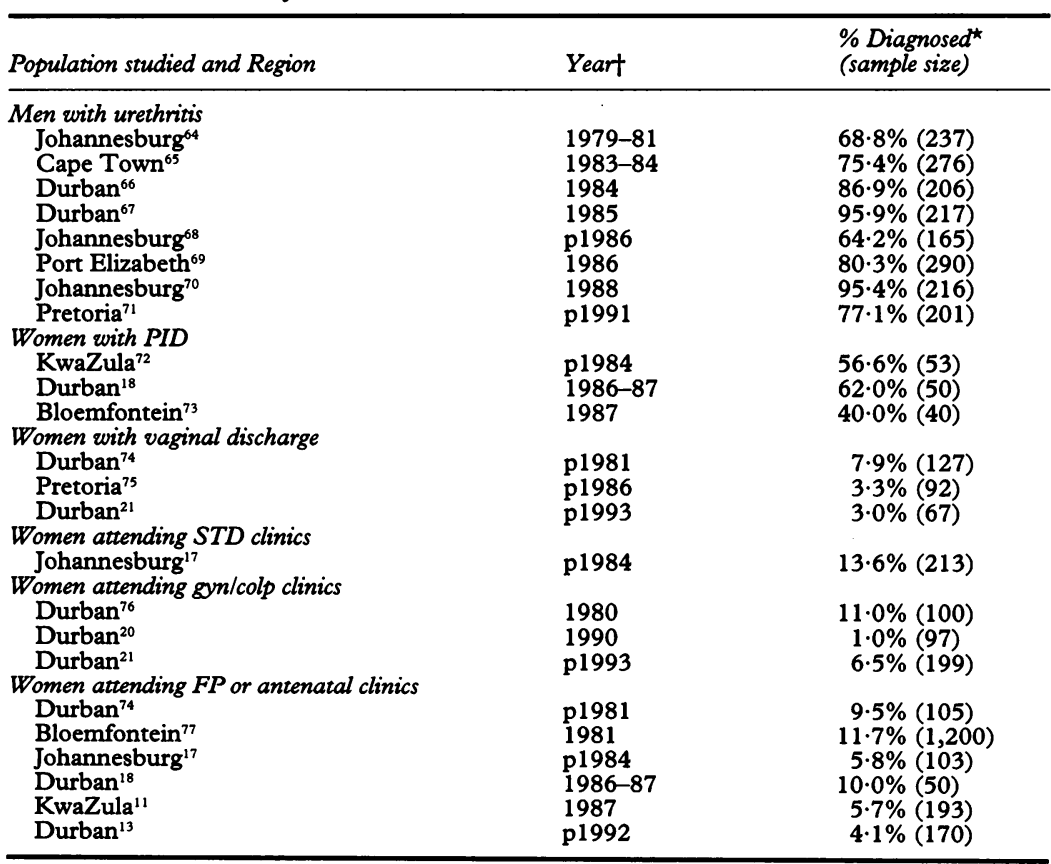

*Diagnosis based on isolation of $N$ gonorrhoeae from specimens obtained from urethral swab (men) or endocervical swab (women).

Date of survey, or if no survey date available, date of publication (p)

PID: pelvic inflammatory disease; STD: sexually transmitted disease; gyn/colp: gynaecological or colposcopy; FP: family planning.
Genital herpes

One of the leading causes of genital ulceration in industrialised countries, herpes simplex virus (HSV) is seen far less frequently in developing countries. In South Africa, HSV is believed to be responsible for a moderately low proportion of GUD cases presenting at STD clinics. There is, however, recognition that, because of the latent and reactivation behaviour pattern of HSV, only a certain proportion of the pool of those infected with genital herpes is identified at any one time.

As shown in table 4, although HSV is present in a relatively small proportion of GUD cases, it is still a significant infection in GUD. Among men with GUD, HSV was isolated in $3 \cdot 3 \%$ to $10 \cdot 0 \%$ cases (median $8 \cdot 8 \%$ ). ${ }^{27-31}$ Three surveys reported prevalence among non-STD clinic attenders. The rates, from a family planning clinic, a gynaecological clinic and a colposcopy clinic, were $1 \%, 2.5 \%$, and $6 \%$ respectively. ${ }^{17}{ }^{2160}$ Rates of $\mathrm{HSV}$ infection, however, are expected to increase considerably as the HIV epidemic in southern Africa evolves.

\section{Non-ulcerative infections \\ Gonococcal infections}

Gonococcal urethritis Internationally, the aetiology of urethritis is complex and appears to vary according to the population groups being sampled. In the US, some attention has focused on apparent racial differences in the aetiology of urethritis; in particular, studies have reported that cases of gonorrhoea are more frequently reported in non-white populations. ${ }^{61-63}$ Certainly, data from black men in South Africa, as shown in table 5, suggest high relative frequencies of gonococcal urethritis (GU). Studies from 1979 to 1991 show that $64 \%-96 \%$ (median $79 \%$ ) of urethritis cases among black men are gonococcal in aetiology. ${ }^{64-71}$ As consistent with American studies, the two South African studies which studied urethritis in Caucasian men reported lower relative frequencies of GU: $42 \cdot 6 \%$ and $50.3 \% .{ }^{6468}$

A significant factor to consider with regard to these apparent racial discrepancies is that, particularly in South Africa, socioeconomic status (SES) is highly correlated with race. SES is, in turn, closely related to physical and financial access to health facilities. Poorer men, who more often than not are black, when faced with the milder symptoms of non-gonococcal urethritis (NGU), may choose to forego a visit to the clinic, in light of the financial, time, and distance constraints. As a result, the true frequency of NGU is most likely underestimated among the poorer, mostly black, population. Thus, racial differences in GU:NGU patterns may be explained by discrepancies in access to facilities and other, possibly economic, factors.

Gonorrhoea in women Data from women who present with an STD show that gonorrhoea is a major infection in salpingitis, or pelvic inflammatory disease (PID). In women with acute 
PID, gonorrhoea, a known initiator of PID, is identified, on average, in $60 \%$ of cases in the KwaZulu-Natal area, and in about $40 \%$ of cases in the Bloemfontein area. ${ }^{187273}$ In the context of other STDs, however, gonorrhoea does not appear extremely frequently: among women presenting with gynaecological complaints other than acute PID, the relative prevalence of gonorrhoea appears to range from $3 \%$ to $14 \% .{ }^{17217475}$

The data also show that there is a significant gonococcal burden among women attending FP and antenatal clinics. As shown in table 5, the range of prevalence rates is $4 \cdot 1 \%$ to $11 \cdot 7 \%, 111317187477$ with three studies reporting rates as high as $10-12 \%, 187477$ levels similar to those found in women presenting at STD clinics. Notably, although these antenatal and FP clinic attenders are assumed to be asymptomatic, this assumption was not verified explicitly in most studies. Of the six studies conducted at FP and antenatal clinics, only two studies reported from population groups which were specified as asymptomatic; these studies reported prevalence rates of $4 \cdot 1 \%$ among antenatal clinic attenders and $10.0 \%$ among FP clinic attenders. ${ }^{13} 18$ The other studies indicated that their survey groups were implicitly asymptomatic, that is, "apparently healthy". The danger with these implicit assumptions is illustrated in two studies in which clinic attenders were asked whether they had any vaginal complaints; when questioned, $55.3 \%$ of FP clinic attenders and $52.9 \%$ of antenatal clinic attenders confirmed that they had vaginal discharge. ${ }^{11} 17$

Gonococcal ophthalmia neonatorum In South Africa, very little has been reported during the last 20 years on rates of gonococcal ophthalmia neonatorum. A 1983-85 study in Cape Town reported an incidence rate of $0.27 \%$ of live births, confirming a previous unpublished rate of $0.25 \%$ of live births in

Table 6 gonorrhoeae isolates resistant to penicillin $G$

\begin{tabular}{|c|c|c|c|}
\hline Region and Year & Source of isolates & $\begin{array}{l}\text { Strains producing } \beta \\
\text { lactamase (PPNG) }\end{array}$ & $\begin{array}{l}\text { Non-PPNG strains } \\
\text { resistant to penicillin } G\end{array}$ \\
\hline \multicolumn{4}{|l|}{ Fohannesburg } \\
\hline $1979-80^{81}$ & STD clinic attenders & $0 \%$ & $0 \%$ \\
\hline $1985^{82}$ & o STD clinic attenders & $13 \%$ & \\
\hline $1988^{70}$ & ơ STD clinic attenders & $13 \%$ & $9 \%$ \\
\hline \multicolumn{4}{|l|}{ Pretoria } \\
\hline $1984^{83}$ & of with urethritis & $4 \%$ & $\cdots$ \\
\hline $1985^{82}$ & STD clinic attenders & $10 \%$ & $\ldots$ \\
\hline \multirow{2}{*}{\multicolumn{4}{|c|}{ Carletonville }} \\
\hline & & & \\
\hline $1983-85^{82} \dagger$ & of STD clinic attenders & $11 \%$ & + \\
\hline \multicolumn{4}{|l|}{ Durban } \\
\hline $1983^{85}$ & of with urethritis & $5 \%$ & \\
\hline $1986-87^{18}$ & with PID & $33 \%$ & $\ldots$ \\
\hline $1987^{11} \mathrm{~g}$ & antenatal clinic attenders & $27 \%$ & $\ldots$ \\
\hline $1987^{67}$ & of with urethritis & $26 \%$ & $1 \%$ \\
\hline \multirow{2}{*}{\multicolumn{3}{|c|}{ antenatal clinic attenders }} & \\
\hline & ot with urethritis & & \\
\hline \multicolumn{4}{|l|}{ Port Elizabeth } \\
\hline \multicolumn{4}{|l|}{$\begin{array}{c}1986^{69} \\
\text { Bloemfontein }\end{array}$} \\
\hline $1981^{77}$ & antenatal clinic attenders & $0 \%$ & $\cdots$ \\
\hline p1987 ${ }^{87}$ & ot with urethritis & $2 \%$ & $\ldots$ \\
\hline
\end{tabular}

*Date of survey or, if no survey date available, date of publication (p).

tIncludes Johannesburg and Pretoria isolates.

$\ddagger$ Proportion not reported, but $\mathrm{MIC}_{90} 0.5 \mu \mathrm{g} / \mathrm{ml}$ with range of $0.008-2 \mu \mathrm{g} / \mathrm{ml}$.

$§$ KwaZulu-Natal region.

STD: sexually transmitted disease; PID: pelvic inflammatory disease; $\delta$ : men; $q$ : women; . . : not reported.
$1980-82 .{ }^{78}$ Although silver nitrate prophylaxis had been used routinely prior to the 1980 s, there is currently no national prophylaxis policy for gonococcal ophthalmia.

Antibiotic resistance Since the detection of the first strains of penicillinase-producing $N$ gonorrhoeae (PPNG) in South Africa, the gonococcus has continued to become resistant to a broad spectrum of antibiotics. South Africa's first PPNG strains, reported in Durban and in Johannesburg in $1977,{ }^{7980}$ were apparently unrelated to emergent West African PPNG strains which were resistant to both penicillin and tetracycline. Subsequently, the prevalence of PPNG strains has increased dramatically, as shown in table 6 . Over a 10 year period, the proportion of isolates of $N$ gonorrhoeae producing $\beta$-lactamase has increased from $<1 \%$ to $13 \%$ in Johannesburg ${ }^{7081}{ }^{82}$; in Durban, PPNG was reported in more than $25 \%$ of gonococcal isolates recovered in the late $1980 \mathrm{s.}{ }^{111867}$ Trends in other centres such as Pretoria, Carletonville, Cape Town, Port Elizabeth, and Bloemfontein appear to lag those of Johannesburg and Durban by several years, but the relative prevalence of PPNG still continues to rise. ${ }^{6569717782-8486}$ In addition, emerging chromosomal resistance to $\beta$-lactam antibiotics in non-PPNG strains is also being documented. ${ }^{7085}$

As compounding evidence made clear that penicillin would no longer be the treatment of choice for gonorrhoea, other antibiotics such as tetracycline, spectinomycin, and cephalosporins were recommended. In 1991, however, a study reported that $56 \%$ of PPNG strains and $34 \%$ of non-PPNG strains isolated in Johannesburg were now resistant to tetracycline. ${ }^{70}$ Currently, all PPNG strains throughout the country are found to be fully susceptible to the newer cephalosporins and quinolone antibiotics, but there are some indications that chromosomal resistance is beginning to threaten the effectiveness of cefuroxime and cefoxitin. ${ }^{84}$

\section{Chlamydial Infections}

Chlamydial urethritis Non-gonococcal urethritis (NGU), 30-40\% of which is caused by Chlamydia trachomatis, is seen far less frequently in public clinics than gonococcal urethritis, for reasons discussed in the gonorrhoea section. In South African studies of public clinics, NGU is diagnosed in $4 \%-36 \%$ of urethritis cases, ${ }^{646568}$ with isolation rates of chlamydia of $12 \cdot 3 \%$ and $14 \cdot 4 \%$, as shown in table 7 .

Studies in South Africa have employed a variety of tools such as serology, direct immunofluorescence (DIF), and isolation to diagnose chlamydial infection. Of these, isolation of $C$ trachomatis is undoubtedly the best indicator of current active chlamydial infection. Some studies have shown that DIF has potentially high sensitivity and specificity in comparison to isolation, but ultimately DIF is subjective and is largely dependent on the experience of the microscopist. ${ }^{88}$ As shown in 
Table 7 Chlamydial infections

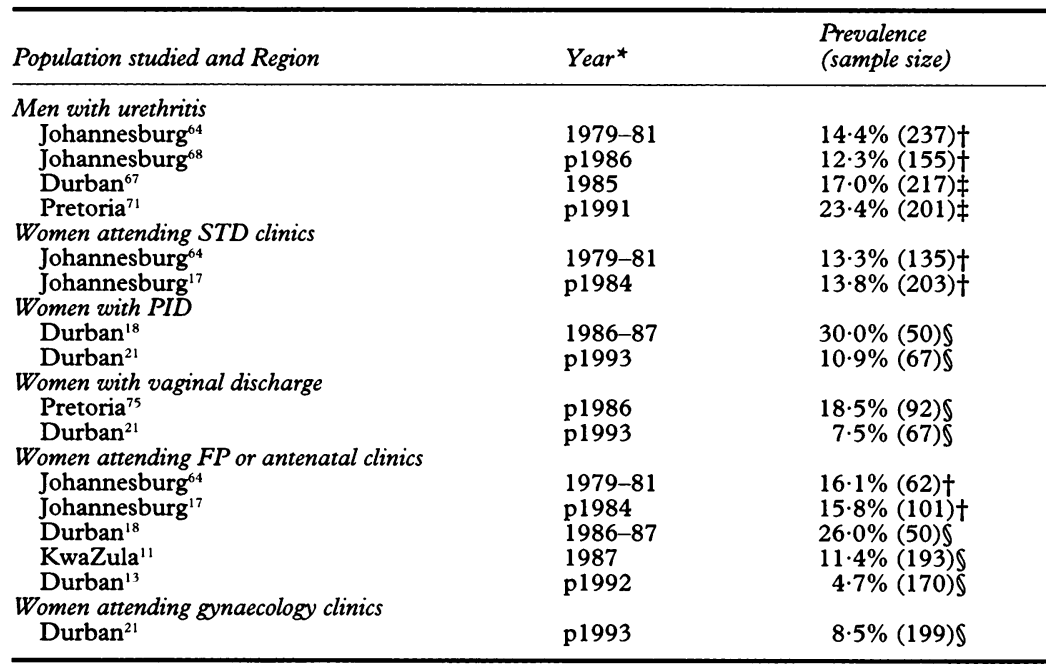

*Date of survey or, if no survey date available, date of publication (p).

†Diagnosis based on isolation of $C$ trachomatis from specimens obtained from urethral swab (men) or endocervical swab (women).

¥Diagnosis based on either isolation of $C$ trachomatis from specimens obtained from urethra swab or on direct immunofluorescence of specimens from urethral swab.

§Diagnosis based on direct immunofluorescence of specimens obtained from endocervical swab. PID: pelvic inflammatory disease; STD: sexually transmitted disease; FP: family planning.

table 7, rates using DIF exhibited considerable variability, but those based on isolation rates are tightly focused.

Serological tests are problematic but are useful in identifying lifetime exposure to chlamydia. Indeed, serological data indicate high levels of exposure to chlamydia among black men despite the low proportion of black men presenting at clinics with apparent chlamydial infection. One study, testing for antichlamydial antibody among black men presenting with urethritis found that $85 \%$ of these men had antibody titres $\geqslant 1: 16 .{ }^{89}$ Another study compared isolation rates of $C$ trachomatis and antichlamydial antibody in black vs. Caucasian men with urethritis and found that, although isolation rates of $C$ trachomatis were higher in Caucasian men, antichlamydial antibody titres were higher in black men. ${ }^{90}$

One reason posited for the low isolation rates in black men despite high antibody titres may be that asymptomatic carriage and repeated reinfection may be more common in this population group. In a study of a black mining community, Ballard et al estimated that at least $65 \%$ of cases of chlamydial urethritis may be asymptomatic. ${ }^{91}$ These asymptomatic infections remain untreated, thus making continued repeated reinfection likely. This reinfection cycle may lead to hyperendemic conditions. In the case of trachoma, another chlamydial infection, hyperendemic conditions result in a failure to isolate $C \mathrm{tra}$ chomatis from the conjunctiva after several reinfection episodes despite the presence of clinical disease. ${ }^{90}$ Thus low isolation rates may not reflect the true prevalence of chlamydia in these populations. Clearly, isolation is not a good diagnostic criterion in hyperendemic areas, and chlamydial infections may be much more common than the isolation studies would indicate.

In South Africa, chlamydia is often associated with gonorrhoea. Mixed gonococcal/ chlamydial infections account for $44 \%$ to $95 \%$ of cases where chlamydia is isolated, while $C$ trachomatis is present in $7 \%-12 \%$ of GU cases. ${ }^{64676871}$

Chlamydial infections in women Data from women suggest that chlamydial infection is common, even among women who would normally be classified as "low-risk". In particular, isolation rates of chlamydia among STD clinic attenders are comparable with those from apparently asymptomatic women attending FP and antenatal clinics. ${ }^{11171864}$ As shown in table 7, $C$ trachomatis has been isolated from approximately $13-14 \%$ of female STD clinic attenders, ${ }^{1764}$ whereas isolation rates of FP and antenatal clinic attenders averaged $16 \% .{ }^{11171864}$ In fact, one study reported that there was no significant difference in prevalence of chlamydia in FP clinic attenders and STD clinic attenders, ${ }^{17}$ and a second noted that there was no significant difference in chlamydial prevalence between FP clinic attenders and women with PID. ${ }^{18}$ In addition, a large seroepidemiological study of over 2400 asymptomatic persons reported chlamydial seropositivity rates (titres $\geqslant 1: 32$ ) of $14 \%$ for women, indicating high levels of previous exposure to chlamydia within the general population. ${ }^{92}$

The role of $C$ trachomatis in the aetiology of PID in South Africa appears complex. PID is recognised as the most frequent diagnosis made at gynaecology out-patient departments, and a review in 1978 estimated that cases of pelvic sepsis comprised approximately onethird of all admissions to gynaecology wards in South Africa. ${ }^{93}$ The majority of these cases, however, had been attributed to infection with $N$ gonorrhoeae with anaerobic superinfection playing a role in the more severe cases.

High titres of antichlamydial antibody $\geqslant 1: 256)$ are detected in a significant proportion of severe and moderately severe PID cases, but $C$ trachomatis is rarely isolated. ${ }^{64}$ However, recent studies have indicated that $C$ trachomatis may be recovered from the endocervix of approximately one-third of asymptomatic women who exhibit cervical excitation tenderness on routine examination (unpublished results). Other data also point to the role of chlamydia in infertility, confirming other international findings. Results from a micro-immunofluorescence study showed that significantly more infertile women with tubal pathology had had chlamydial exposure than had pregnant controls. ${ }^{89}$ Moreover, in another study comparing pregnant women to women with acute PID, a lower prevalence of $C$ trachomatis seropositivity was associated with pregnancy. ${ }^{94}$

\section{Vaginal Infections}

Trichomoniasis and genital candidiasis High rates of Trichomonas vaginalis and Candida albicans have consistently been detected in virtually all population groups of women surveyed in published studies (table 8). Household surveys and surveys of FP clinic 
Table 8 Isolation rates of $T$ vaginalis and $C$ albicans

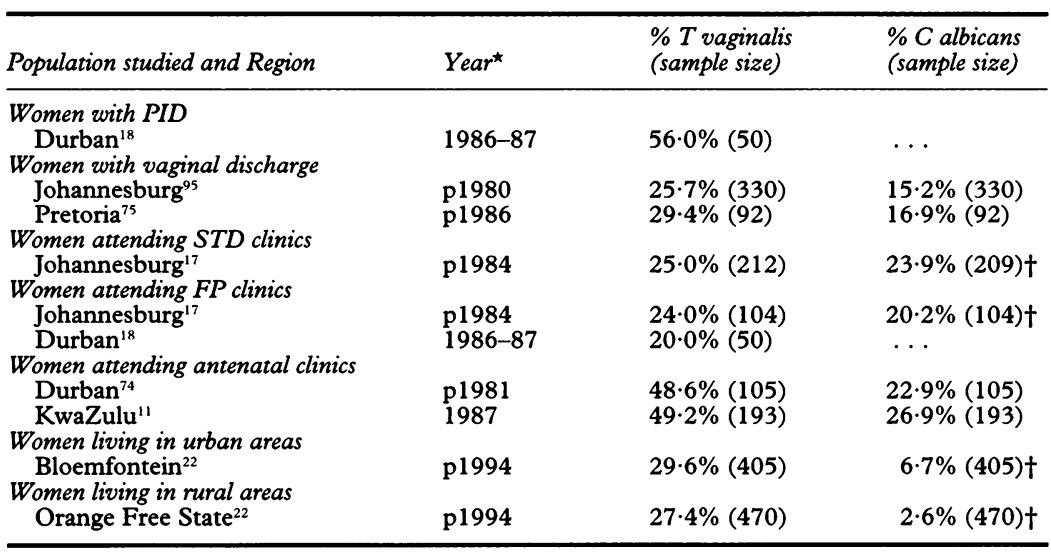

¿Date of survey, or if no survey date available, date of publication (p).

†Includes Candida spp.

PID: pelvic inflammatory disease; STD: sexually transmitted disease; FP: family planning, ... not reported.

attenders and antenatal clinic attenders report trichomoniasis rates of $20 \%$ to $49 \%$ of these presumably asymptomatic groups. ${ }^{1117182274}$ One report noted no difference in rates of trichomoniasis or genital candidiasis between FP clinic attenders and STD clinic attenders. ${ }^{17} T$ vaginalis and $C$ albicans are often found together: in more than $50 \%$ of total vaginal infections in women seeking antenatal care, the two pathogens were found concurrently. ${ }^{74}$

Bacterial vaginosis Bacterial vaginosis, caused by the combination of Gardnerella vaginalis and mixed anaerobic bacteria, is also an important cause of vaginal discharge. Although several studies reported isolation rates of $G$ vaginalis, these rates are not particularly helpful because many women may be colonised by $G$ vaginalis without vaginosis. One study, however, diagnosing bacterial vaginosis on the basis of the characteristic "clue cells", found that $46 \cdot 8 \%$ of STD clinic attenders, and $55.5 \%$ of FP clinic attenders had bacterial vaginosis. ${ }^{17}$ Another study reported that $60.9 \%$ of women presenting with vaginal discharge were found to have bacterial vaginosis. ${ }^{75}$

Table 9 HIV seroprevalence rates among antenatal clinic attenders ${ }^{109-113}$

\begin{tabular}{|c|c|c|c|c|c|}
\hline \multirow[b]{2}{*}{ Region/Province } & \multicolumn{5}{|l|}{ Year } \\
\hline & 1990 & 1991 & 1992 & 1993 & 1994 \\
\hline KwaZulu-Natal & $\begin{array}{l}1 \cdot 6 \% \\
(1 \cdot 7-2 \cdot 2 \%)\end{array}$ & $\begin{array}{l}2 \cdot 9 \% \\
(2 \cdot 2-3 \cdot 6 \%)\end{array}$ & $\begin{array}{l}4 \cdot 7 \% \\
(3 \cdot 6-6 \cdot 0 \%)\end{array}$ & $\begin{array}{l}9 \cdot 6 \% \\
(8 \cdot 0-11 \cdot 2 \%)\end{array}$ & $\begin{array}{l}14 \cdot 4 \% \\
(12 \cdot 2-16 \cdot 5 \%)\end{array}$ \\
\hline Free State & $\begin{array}{l}0 \cdot 6 \% \\
(0 \cdot 1-1 \cdot 1 \%)\end{array}$ & $\begin{array}{l}1 \cdot 5 \% \\
(0 \cdot 7-2 \cdot 3 \%)\end{array}$ & $\begin{array}{l}2 \cdot 8 \% \\
(1 \cdot 9-3 \cdot 8 \%)\end{array}$ & $\begin{array}{l}4 \cdot 1 \% \\
(3 \cdot 0-5 \cdot 2 \%)\end{array}$ & $\begin{array}{l}9 \cdot 2 \% \\
(7 \cdot 9-10 \cdot 4 \%)\end{array}$ \\
\hline Transvaal & $\begin{array}{l}0.5 \% \\
(0 \cdot 3-0 \cdot 8 \%)\end{array}$ & $\begin{array}{l}1 \cdot 1 \% \\
(0 \cdot 7-1 \cdot 5 \%)\end{array}$ & $\begin{array}{l}2 \cdot 2 \% \\
(1 \cdot 7-2 \cdot 6 \%)\end{array}$ & $\begin{array}{l}3 \cdot 1 \% \\
(2 \cdot 5-3 \cdot 7 \%)\end{array}$ & \\
\hline Eastern Transvaal & & & & & $\begin{array}{l}12 \cdot 2 \% \\
(11 \cdot 6-12 \cdot 7 \%)\end{array}$ \\
\hline Northern Transvaal & & & & & $\begin{array}{l}3 \cdot 0 \% \\
(2 \cdot 4-3 \cdot 7 \%)\end{array}$ \\
\hline Gauteng & & & & & $\begin{array}{c}6 \cdot 4 \% \\
(5 \cdot 6-7 \cdot 3 \%)\end{array}$ \\
\hline North-West & & & & & $\begin{array}{l}6 \cdot 7 \% \\
(4 \cdot 6-8 \cdot 8 \%)\end{array}$ \\
\hline Cape & $\begin{array}{l}0.2 \% \\
(0 \cdot 1-0.3 \%)\end{array}$ & $\begin{array}{l}0.4 \% \\
(0.2-0.6 \%)\end{array}$ & $\begin{array}{l}0.7 \% \\
(0.4-0.9 \%)\end{array}$ & $\begin{array}{l}1.3 \% \\
(0.9-1 \cdot 8 \%)\end{array}$ & \\
\hline Northern Cape & & & & & $\begin{array}{l}1 \cdot 8 \% \\
(1 \cdot 1-2 \cdot 5 \%)\end{array}$ \\
\hline Eastern Cape & & & & & $\begin{array}{c}4 \cdot 5 \% \\
(3 \cdot 9-5 \cdot 2 \%)\end{array}$ \\
\hline Western Cape & & & & & $\begin{array}{l}1 \cdot 2 \% \\
(0 \cdot 8-1 \cdot 6 \%)\end{array}$ \\
\hline South Africa & $\begin{array}{l}0 \cdot 8 \%{ }^{\star} \\
(0 \cdot 6-1 \cdot 0 \%)\end{array}$ & $\begin{array}{l}1 \cdot 5 \%{ }^{\star} \\
(1 \cdot 2-1 \cdot 6 \%)\end{array}$ & $\begin{array}{l}2 \cdot 7 \%^{\star} \\
(2 \cdot 3-3 \cdot 1 \%)\end{array}$ & $\begin{array}{l}4 \cdot 3 \% \\
(3 \cdot 8-4 \cdot 7 \%)\end{array}$ & $\begin{array}{l}7 \cdot 6 \% \\
(7 \cdot 0-8 \cdot 1 \%)\end{array}$ \\
\hline
\end{tabular}

$95 \%$ confidence intervals, $(-)$.

$\star$ Estimate excludes Transkei, Bophuthatswana, Venda, Ciskei.
The data are clear in showing that trichomoniasis, genital candidiasis, and bacterial vaginosis are highly prevalent and are often asymptomatic or inapparent. Although these infections are not considered to be sexually transmitted, bacterial vaginosis may ultimately be a factor related to the aetiology of PID. That many of these vaginal infections, when they are symptomatic, present with, and often mask, the more serious infections caused by $C$ trachomatis and $N$ gonorrhoeae indicate that these vaginal pathogens are also important to identify and control.

\section{Human papillomavirus infections}

Although South Africa is believed to have one of the highest prevalences of human papillomavirus (HPV) infections and cervical intraepithelial neoplasia (CIN) in the world, ${ }^{9697}$ there have been few studies documenting the prevalence of HPV in South Africa. Three studies during the past 10 years have attempted to estimate HPV prevalence, but all of them used cytological criteria for diagnosis, the sensitivity and specificity of which is unknown. One study, retrospectively diagnosing HPV from preserved hysterectomy specimens (from women who had been diagnosed with leiomyoma but for whom intra-epithelial carcinoma had been ruled out), reported extremely high prevalence rates of $66 \%$ and $64 \%$ for 1972 and 1982 , respectively. ${ }^{98}$ Another retrospective study in Cape Town noted an HPV prevalence rate of $27 \%$ in Papanicolou (Pap) smears of pregnant patients, and reported an increase in "incidence" of HPV at a tertiary hospital between 1982 and $1988 .{ }^{99}$ A 1989 study, however, also diagnosing HPV on the basis of cytology observed in Pap smears reported a prevalence of $5.7 \%$ in pregnant women. ${ }^{11}$ Notably, these last two studies were not explicit in their cytological criteria for HPV, and it is known that intra-observer and inter-observer reproducibility for cytological diagnosis of HPV is weak. ${ }^{100} 101$ More accurate and reliable estimations of HPV prevalence in the future will need to rely on more sophisticated and reliable methods such as DNA hybridisation. In recent studies, hybridisation techniques have been used, but usually to classify HPV types found in cervical intraepithelial neoplasia and genital warts. These studies have noted that a significant proportion of HPV genotypes found in South Africa appear to be from "minor" or as yet unclassified genotype classes. ${ }^{102-106}$

\section{HIV and the classic STDs}

The link between HIV and many of the classic STDs has been well-documented internationally. ${ }^{1}$ Strong evidence exists from prospective studies for increased transmission of HIV in the presence of genital ulcer disease as a syndrome, and of chancroid, syphilis, and genital herpes in particular. ${ }^{12}$ The evidence for nonulcerative diseases is weaker but still compelling, and several prospective studies in commercial sex workers have documented 


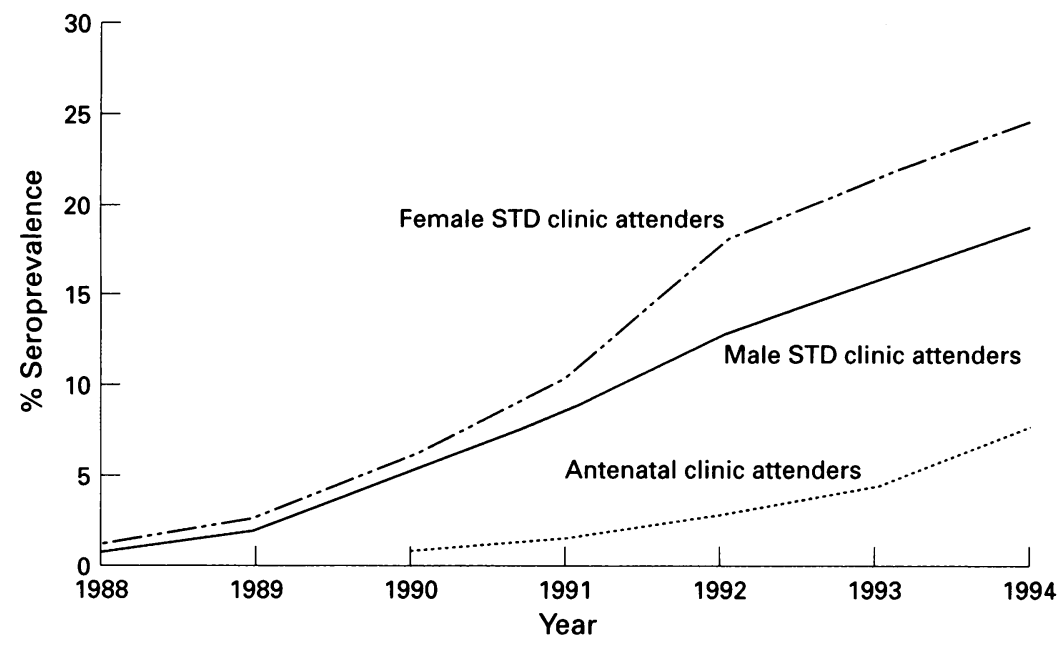

Figure HIV seroprevalence among STD clinic attenders (fohannesburg) ${ }^{114}$ and antenatal clinic attenders (national) ${ }^{109-113}$ up to $90 \%$ of women attending FP and antenatal clinics have at least one STD. More specifically, this review shows data revealing that up to $15 \%$ of FP clinic and antenatal clinic attenders are seropositive for syphilis, $16 \%$ may be infected with chlamydia, $8 \%$ may be infected with gonorrhoea, and as many as $20-50 \%$ of women have vaginal infections. This high burden of disease, compounded with the 15-month doubling period of HIV seroprevalence and the complex interactions between HIV and STDs, starkly illustrate the gravity of the current STD problem.

Overall, the STD data are substantial but somewhat incomplete. Published literature has tended to focus on certain infections and survey populations; thus, while there is fairly comprehensive, if varied, reporting on syphilis and gonorrhoea, there is considerably less information on other epidemiologically important infections such as chlamydia and HPV. Moreover, for most infections, data have been reported only from STD facilities in the major urban centres; hence, relative prevalence estimates are abundant, but "general population" prevalence rates, particularly from rural areas, are scarce.

These data also highlight other widespread problems experienced in the study of STDs in Africa. The exact scope of syphilis has been difficult to define because of deficiencies in current syphilis serological methods. Syphilis serology tests are imprecise in diagnosing active syphilis, and interpretation of serological information poses a particular problem in cases of positive treponemal tests alongside negative reagin tests. In addition, diagnosis of gonorrhoea and chlamydia in women requires endocervical swabs, the invasive nature of which has restricted the scope of many studies. Isolation of $C$ trachomatis under hyperendemic conditions is also problematic. With the development of non-invasive diagnostic techniques such as testing of first-catch urine specimens using amplified molecular techniques, the collection of more accurate community-based data on these infections will become more viable.

Sorely needed temporal data on STDs are conspicuously missing. This dearth of data is primarily a result of a lack of a surveillance system which encompasses the major STDs. Currently, syphilis is the only STD for which surveillance is on-going, and antenatal clinic attenders are the only sentinel group. However, high rates of tubal-related infertility in South Africa and the implicit exclusion of infertile women from the sentinel group of antenatal clinic attenders mean that the use of antenatal attenders as the only sentinel group for sexually transmitted disease surveillance merits review. Overall, this bird's-eye view of the data strongly argues for a more comprehensive system of STD surveillance. At this date, the only STD notifiable in South Africa is congenital syphilis, which was designated a notifiable condition in 1991. Because of the notorious under-reporting of notifiable conditions in general, however, the quality of this notification data is questionable, and the relepicture of STDs and STD data in SOU Africa. The most compelling finding is undoubtedly that STDs are endemic in South Africa. Studies show that around $17 \%$ of antenatal clinic attenders harbour at least one urogenital tract infection, and between $49 \%$ and 
vance of conferring notifiability status to other STDs is unclear. The quality of syphilis seroprevalence data among antenatal clinic attenders is better, but this monitoring also only began in late 1991. Notably, a national STD surveillance system is currently in development. This system will attempt to include public and private facilities sampled from each province, and will attempt to collect both syndromic data and disease-specific data from patients with a particular disease syndrome.

In South Africa, the high prevalence of mixed infections, antibiotic resistance, prevalence of asymptomatic infections, diversity of pathogens, and atypical presentation of disease mean that both data collection and health policies must be adapted to suit local conditions. For example, the flow charts used for syndromic management must account for the presence of LGV and genital herpes.

In addition to these aspects of STD infections, STD control in South Africa must now face the operational challenge of a notoriously fragmented health system. Although a comprehensive and cohesive approach to HIV/STDs within the health services is currently being planned, the country's legacy of fragmentation has made a thorough review of STD services in South Africa difficult. A recent assessment of STD services in the Gauteng province, however, has provided an in-depth view of services which may be typical of those in highly urbanised provinces. ${ }^{115}$ In Gauteng, a province which includes the cities of Johannesburg and Pretoria, public STD services in urban areas are provided by (i) local authorities, which run vertical STD programmes, (ii) the provincial administration which provides STD services through small vertical programmes for rural and peri-urban areas, and (iii) through comprehensive hospital-based Community Health Care Centres. In addition, there is a highly developed private sector comprised of private general practitioners, traditional healers, and pharmacists. There are also industrial (work-place based) clinics and private not-for-profit services. The report found that, although public STD services are theoretically within the scope of responsibility of the local authorities, STD care is limited in terms of times and venues available, and is not considered to be a part of the basic package of services. In addition, improper case management appeared to be a serious problem in many local authority clinics, and notably, among private general practitioners. The report also noted that private providers, and not the public services, saw a significant proportion, and possibly the majority, of STD cases.

Overall, perhaps one of the biggest STD policy gaps still found in South Africa is the lack of routine STD screening. Although HIVpositive patients and STD patients in some Johannesburg clinics are automatically screened for syphilis, serological screening for syphilis is not routine practice in general at many facilities, even where STD patients are seen. With the broader availability of rapid and non-invasive tests, broader screening for a variety of diseases may become more feasible. Such STD screening will be important for the prevention of complications such as infertility, and will also be particularly important for the prevention of congenital syphilis. Few hospitals routinely perform an RPR test on women presenting for delivery; because, on average, $1 / 4$ to $1 / 3$ of women presenting for delivery have unknown syphilis status, this type of screening may prevent significant postnatal morbidity and mortality caused by congenital syphilis.

The development of the STD surveillance system augurs well for the future of STD data collection, but the fruits of surveillance will need to be directly linked and fed back to the health services and to policy-makers. With the rapidly emerging HIV epidemic, the heavy STD burden, and the resource-intensiveness of interventions for STD and HIV, STD surveillance, streamlining of STD services, and focused STD policies will be more important than ever in the new South Africa. This work was supported by Metropolitan Life, the US Agency
for International Development through a grant from the AIDS Consortium, and the Medical Research Council of South Africa. We express our appreciation to Derek Yach, Salim Africa. We express our appreciation to Derek Yach, Salim
Abdool Karim, Neil Cameron, Nicol Coetzee, and Michelle Abdool Karim, Neil Cameron, Nicol Coetzee,
Galloway for their reviews of an earlier draft.

1 Wasserheit JN. Epidemiological synergy. Interrelationships between human immunodeficiency virus infection and other sexually transmitted diseases. Sex Transm Dis and other sexually

2 Cameron DW, D'Costa LJ, Maitha GM, et al. Female to male transmission of human immunodeficiency virus type 1: risk factors for seroconversion in men. Lancet 1989;2:403-7.

3 Laga M, Manoka A, Kivuvu M, et al. Non-ulcerative sexually transmitted diseases as risk factors for HIV-1 transmission in women: results from a cohort study. AIDS 1993;7:93-102.

4 Murray JF. Endemic syphilis or yaws? $S$ Afr Med $\mathcal{f} 1957$ 33:821-4.

5 Kark SL. The social pathology of syphilis in Africans. $S$ Afr Med f 1949;23:77-84.

6 Jaffe HW, Musher DM. Management of the reactive syphilis serology. In: Holmes KK, Mårdh P-A, Sparling PF, Wiesner PJ, Cates W, Lemon SM, Stamm WE, eds Sexually Transmitted Diseases. 2nd ed. New York McGraw-Hill, 1990;935-9.

7 Ballard RC. Syphilis serology and its interpretation in southern African context. Johannesburg: STD Reference Centre; 1994. Report for PWV STD Work Group.

8 Mahomed MF, Mokaila PP, Barron C, Crewe-Brown H. The prozone phenomenon in syphilis serology in antenatal patients. S Afr 7 Sex Transm Dis 1984;4:29-31.

9 Gonin JM. Syphilis - an appraisal of the Groote Schuur Hospital antenatal screening programme. S Afr Med $\mathscr{f}$ Hospital anten

10 Manning B, Moodley J, Ross S. Syphilis in pregnant black women. $S$ Afr Med $\mathcal{F} 1985 ; 67: 966-7$.

11 O'Farrell N, Hoosen AA, Kharsany ABM, van den Ende J Sexually transmitted pathogens in pregnant women in rural South African community. Genitourin Med $1989 ; 65: 276-80$

12 Coetzee N. Syphilis in women attending antenatal clinics in the Western Cape: a pilot investigation into the use of a laboratory based surveillance scheme. University University of Cape Town Department of Community Health Working Paper 94/1. Cape Town, 1994.

13 Dietrich M, Hoosen A, Moodley J, Moodley S. Urogenital tract infections in pregnancy at King Edward VIII Hospital, Durban, South Africa. Genitourin Med 1992;68:39-41.

14 Venter A, Pettifor JM, Exposto FD, Sefuba $M$. Congenital syphilis-who is at risk? A prevalence study at Baragwanath Hospital, Johannesburg, 1985-1986. S Afr Med f 1989;76:93-5.

15 Swingler GH, van Coeverden de Groot HA. The antenata prevention of congenital syphilis in a peri-urban settlement. S Afr Med F 1993;83:34-5.

16 Mlisana KP, Monokoane S, Hoosen AA, Moodley J, Adhikari M, Taylor L. Syphilis in the "unbooked" preg nant woman. S Afr Med ₹ 1992;82:18-20.

17 Fehler HG, Duncan MO, Bilgeri YR, Ballard RC Sexually transmitted diseases amongst urban black women. $S$ Afr $\mathcal{F}$ Sex Transm Dis 1984;4:48-53.

18 Hoosen AA, Quinlan DJ, Moodley J, Kharsany ABM, van den Ende J. Sexually transmitted pathogens in acute 
pelvic inflammatory disease. $S$ Afr Med $f$ 1989;76: $251-4$.

19 Klugman KP, Patel J, Sischy A, McIntyre JA. Serologica markers of sexually transmitted diseases associated with HIV-1 infection in pregnant black women. $S$ Afr Med $\mathcal{F}$ 1991;80:243-4.

20 Moodley J, Hoosen AA, Naidu S, Mayat N, Kharsan ABM. HIV status and sexually transmitted pathogens in women attending a colposcopy clinic. $S$ Afr 7 Epid Inf 1992;7:24-6

21 Moopanar D, Hoosen AA, Moodley J, Tait DR, Moodley C. Human immunodeficiency virus, syphilis and mucopurulent cervicitis in gynaecology outpatient clinic attenders. South Afr ₹ Epidemiol Infect 1993;8:74-6.

22 Cronjé HS, Joubert G, Muir A, Chapman RD, Divall P Bam RH. Prevalence of vaginitis, syphilis and HIV infection in women in the Orange Free State. $S$ Afr Med infection in wome

23 Ramphele MA, Heap M. Health status of hostel dwellers Part II. Infant mortality and prevalence of diabetes, hypertension and syphilis among adults. $S$ Afr Med $\mathcal{F}$ 1991;79:702-5.

24 Hamilton RA, Perlman T, deSouza JL. 200 unbooked pregnant women in the Transvaal-an overview. In: Proceedings of the Fourth Conference on Priorities in Perinatal Care in South Africa; 1985 Mar 12-15; Drakensberg, Natal. Johannesburg: University of the Witwatersrand Department of Paediatrics, 1985:26-30.

25 Loenig WEK, Broughton M. The unbooked patient-why does she not book? In: Proceedings of the Fourth does she not book? In: Proceedings of the Fourth Conference on Priorities in Perinatal Care in South
Africa; 1985 Mar 12-15; Drakensberg, Natal. Johannesburg: University of the Witwatersrand Department of Paediatrics, 1985:31-33.

26 Pattinson A, Roussow L. A prospective controlled study of the unbooked mothers at Tygerberg Hospital. In Proceedings of the Fourth Conference on Priorities in Perinatal Care in South Africa; 1985 Mar 12-15; Drakensberg, Natal. Johannesburg: University of the Witwatersrand Department of Paediatrics, 1985:34-7.

27 Duncan MO, Bilgeri YR, Fehler HG, Ballard RC. The diagnosis of sexually acquired genital ulcerations in 1981;1:20-3.

28 Crewe-Brown HH, Krige FK, Davel GH, et al. Genital ulceration in males in Ga-Rankuwa Hospital, Pretoria. Afr Med f 1982;62:861-3

29 Coovadia YM, Kharsany A, Hoosen AA. The microbia aetiology of genital ulcers in black men in Durban South Africa. Genitourin Med 1985;61:266-9.

30 Dangor Y, Fehler G, Exposto F, Koornhof HJ. Causes and treatment of sexually acquired genital ulceration in southern Africa. $S$ Afr Med $\mathcal{F}$ 1989;76:339-41.

31 O'Farrell N, Hoosen AA, Coetzee KD, van den Ende J. Genital ulcer disease in men in Durban, South Africa. Genitourin Med 1991;67:322-6.

32 Duncan MO, Ballard RC, Bilgeri YR, Fehler HG Sexually acquired genital ulcerations in urban black Sexually acquired genital ulcerations in urba
women. $S A$ fr $₹$ Sex Transm Dis 1984;4:23-7.

33 O'Farrell N, Hoosen AA, Coetzee KD, van den Ende J Genital ulcer disease in women in Durban, South Africa. Genitourin Med 1991;67:322-6.

34 Sischy A, Exposto F, Dangor Y, et al. Syphilis serology in patients with primary syphilis and non-treponemal sexually transmitted diseases in southern Africa. Genitourin Med 1991;67:129-32.

35 Opai-Tetteh ET, Hoosen AA, Moodley J. Re-screening for syphilis at the time of delivery in areas of high prevalence. $S$ Afr Med F 1993;83:725-6.

36 Department of National Health and Population Development. Incidence rates of syphilis and congenital Development. Incidence rates of syphilis and congenital syphilis in four local authorities, 1976-80

37 Bam RH, Cronjé HS, Muir A, Griessel DJ, Hoek BB Syphilis in pregnant patients and their offspring. Int $\mathscr{f}$ Gynaecol Obstet 1994;44:113-8.

38 Ross SM, MacPherson T, Wallace J, Khatree MH, Naeye RL, Appelbaum PC. Unsuccessful pregnancies-report on 200 perinatal postmortems. S Afr Med $\mathcal{F} 1978 ; 53$ 828-9.

39 Woods DL, Draper RR. A clinical assessment of stillborn infants. S Afr Med f 1980;57:441-3.

40 Ross SM, MacPherson T, Naeye RL, Khatree MHD, Wallace JA. Causes of fetal and neonatal mortality in a South African Black community. S Afr Med $\mathcal{F} 1982 ; 61$ : 905-8.

41 Delport SD. Serological screening of cord blood for syphilis. $S$ Afr Med $\mathcal{F}$ 1988;73:528-9.

42 De Jong G, Pattinson RC, Odendaal HJ. Influence of perinatal care on stillbirths in patients of low socio-economic class. $S$ Afr Med $\mathcal{F} 1988 ; 74: 53-4$

43 Delport SD. Congenital syphilis-a plea for prevention [letter]. S Afr Med f 1988;74:311.

44 Delport SD, Rothberg AD. Congenital syphilis-now a notifiable disease [editorial]. S Afr Med $\mathcal{F} 1992 ; 81$ : 288-9.

45 Ballot $\mathrm{DE}$, Rothberg $\mathrm{AD}$. Congenital syphilis as a notifiable disease. S Afr Med f 1993;83:721-3.

46 Department of National Health and Population Development. Congenital syphilis: a notifiable medical condition. Epidemiological Comments 1992;19:176.

47 Dangor Y, Ballard RC, Exposto F, Fehler G, Miller SD, Koornhof HJ. Accuracy of clinician diagnosis of genital ulcer disease. Sex Transm Dis 1990;17:184-9.
48 O'Farrell N, Hoosen AA, Coetzee KD, van den Ende J. Genital ulcer disease: accuracy of clinical diagnosis and strategies to improve control in Durban, South Africa. Genitourin Med 1994;70:7-11.

49 Plummer FA, D'Costa LJ, Nsanze H, Dylewski J Karastra P, Ronald AR. Epidemiology of chancroid and Haemophilus ducreyi in Nairobi, Kenya. Lancet 1983;2 1293-4.

50 Bilgeri YR, Ballard RC, Duncan MO, Mauff AC, Koornhof HJ. Antimicrobial susceptibility of 103 strains of Haemophilus ducreyi isolated in Johannesburg. Antimicrob Agents Chemother 1982;22:686-8.

51 Dangor Y, Miller SD, Exposto F, Koornhof HJ Antimicrobial susceptibility of southern African isolates of Haemophilus ducreyi. Antimicrob Agents Chemother 1988;32:1458-60.

52 Ricono $M$. Yaws and similar diseases in South Africa. $S$ Afr Med Record 1916;14:83-8.

53 Freinkel AL. The enigma of granuloma inguinale in South Africa. S Afr Med $\mathcal{F}$ 1990;77:301-3.

54 Wistrand $R$, Wegerhoff $F$. Granuloma inguinale in the Eastern Transvaal. $S$ Afr Med $\mathcal{f} 1985 ; 67: 13-5$.

55 O'Farrell N. Trends in reported cases of donovanosis in Durban, South Africa. Genitourin Med 1992;68:269-70.

56 Freinkel AL, Counihan RJ. Granuloma inguinale (donovanosis) in South Africa. $S$ Afr Med $\mathcal{A}$ 1983;63:599-601.

57 Bassa A, Hoosen A, Moodley J, Bramdev A. Granulom inguinale (donovanosis) in women: an analysis of 61 cases from Durban, South Africa. Sex Transm Dis 1993 20:164-7.

58 Faber BL. Donovanosis (granuloma inguinale) in the Orange Free State [letter]. S Afr Med f 1987;71:196.

59 Hayes LJ, Yearsley P, Treharne JD, Ballard R, Fehler G Ward ME. Evidence for naturally occurring recombination in the gene encoding the major outer membrane protein of lymphogranuloma venereum isolates of Chlamydia trachomatis. Infect Immun 1994;62:5659-63.

60 Miller SD. Inapparent genital herpes simplex infection in women attending a colposc

61 Aral SO, Holmes KK. Epidemiology of sexual behaviour and sexually transmitted diseases. In: Holmes KK, Mårdh P-A, Sparling PF, Wiesner PJ, Cates W, Lemon SM, Stamm WE, eds. Sexually Transmitted

62 Rice RJ, Aral SO, Blount JH, Zaida AA. Gonorrhea in the United States 1975-1984: is the giant only sleeping? Sex Transm Dis 1987;14:83-7.

63 Barnes RC, Holmes KK. Epidemiology of gonorrhea: current perspectives. Epidemiologic Reviews 1984;6:1-30.

64 Ballard RC, Fehler HG, Duncan MO, van der Wat IJ. Urethritis and associated infections in Johannesburgthe role of Chlamydia trachomatis. S Afr $\mathcal{f}$ Sex Transm Dis 1981;1:24-6.

65 Simpson JA, Oliver SP. Beta-lactamase producing isolates of Neisseria gonorrhoeae. S Afr ₹ Epid Infect 1987;2:33-8

66 Coovadia YM, Dada M, Kharsany A, Ramsaroop U, Bhamjee A. The emergence of penicillinase-producing strains of Neisseria gonorrhoeae in Durban. $S$ Afr Med $\mathcal{F}$ 1984;65:835-7.

67 Hoosen A, van den Ende J, Kharsany A. The aetiology of acute urethritis in black males in Durban, South Africa and penicillin susceptibility of Neisseria gonorrhoeae isolates. S Afr F Epid Infect 1987;2:4-6.

68 Ballard RC, Fehler HG, Bilgeri YR, Duncan MO, Koornhof $\mathrm{HJ}$. A clinical and microbiological evaluation of the treatment of urethritis with minocycline. $S$ Afr Epid Infect 1986;1:19-24.

69 Meiring JA, Kemp E, Jennings DL, Mdhlovu M Koornhof $\mathrm{HJ}$. High-level penicillin-resistant gonococcal Koornhof HJ. High-level penicillin-resistant gonococcal

70 Dangor Y, Naidoo S, Ballard RC. The changing patterns of antimicrobial susceptibilities of Neisseria gonorrhoeae isolated in Johannesburg. S Afr $\mathcal{F}$ Epid Infect 1991;6:34-6.

71 Crewe-Brown HH, Adam A, Ebrahim O, Mahomed MF, Pochee E. The aetiology of acute urethritis in a souther African general practice. $S$ Afr $₹$ Epid Infect 1991;6:31-3.

72 Allen L, Schoon M. Diagnostic laparoscopy and management of patients with confirmed acute pelvic inflammatory disease. $S$ Afr Med $¥ 1984 ; 65: 201-2$.

73 Burchell HJ, Cronjé HS, de Wet IJ. Efficacy of differen antibiotics in the treatment of pelvic inflammatory disantibiotics in the treatment of pel.

74 Hoosen AA, Ross SM, Mulla MJ, Patel M. The incidence of selected vaginal infections among pregnant urban Blacks. S Afr Med f 1981;59:827-9.

75 Pochee E, Crewe-Brown HH, Adam A, Ebrahim O Microbiology of vaginal discharge. $S$ Afr $\mathcal{F}$ Epidemiol Infect 1986;1:91-3.

76 Vink G, Moodley J. Gonorrhoea in black women attend ing a gynaecological outpatient department. $S$ Afr Med $\mathscr{f}$ 1980;558:901-2.

77 Welgemoed NC, Mahaffey A, van den Ende J. Prevalence of Neisseria gonorrhoeae infection in patients attending an antenatal clinic. $S$ Afr Med $\mathcal{F} 1986 ; 69: 32-4$

78 Lund RJ, Kibel MA, Knight GH, van der Elst C. Prophylaxis against gonococcal ophthalmia neonatoProphylaxis against gonococcal
rum. $S$ Afr Med f 1987;72:620-2.

79 Robins-Brown RM, Gaillard MRC, Koornhof HJ, Mauff AC. Penicillinase-producing Neisseria gonorrhoeae AC. Penicillinase-producing
[letter]. S Afr Med $\mathcal{F} 1977 ; 51: 568$.

80 Hallet AF, Appelbaum PC, Cooper R, Mokgokong S, Monale D. Penicillinase-producing Neisseria gonorrhoea from South Africa [letter]. Lancet 1977;1:1205. 
81 Liebowitz LD, Ballard RC, Koornhof HJ. In vitro susceptibility and cross-resistance of South African isolates of Neisseria gonorrhoeae to 14 antimicrobial agents. ontimicrob Agents Chemother 1982;22:598-603.

82 Dangor Y, Mdhlovu M, Duncan MO, Exposto F, Fehler HG, Ballard RC. The emergence of penicillinase-producing strains of Neisseria gonorrhoeae in southern Africa. S Afr f Sex Transm Dis 1985/6;5:55-7.

83 Crewe-Brown H, Mahomed M, Pochee E, Shewan K, Adams A, Ebrahim $\mathrm{O}$. Penicillinase-producing strains of Neisseria gonorrhoeae in Pretoria [letter]. $S$ Afr Med $f$ 1985;67:159.

84 Coovadia YM, van den Ende J, Hoosen A, Kharsany A. Susceptibility of penicillinase-producing and non-penicillinase-producing strains of Neisseria gonorrhoeae isolated in Durban, South Africa to $15 \beta$-lactam antibiotics. Sex Transm Dis 1988;15:30-4.

85 Coovadia YM, Kharsany A, Ramsaroop U. Antimicrobial susceptibility of Neisseria gonorrhoeae isolated in Durban South Africa. $\mathrm{Br} 7$ Venereal Dis 1984;60:306-8.

86 Ison CA, Roope NS, Dangor Y, Radebe F, Ballard R. Antimicrobial susceptibilities of Neisseria gonorrhoeae in southern Africa: influence of geographical source of infection. Epidemiol Infect 1993;10:297-305.

87 Dove $M$, Wende L, Anthony $M$, van den Ende J. Gonococcal urethritis in Bloemfontein: emergence of penicillinase-producing strains of Neisseria gonorrhoeae. $S$ Afr $\mathcal{F}$ Epidemiol Infect 1987;2:33-8.

88 Stamm EE, Mårdh P-A. Chlamydia trachomatis. In: Holmes KK, Mårdh P-A, Sparling PF, Wiesner PJ, Cates W, Lemon SM, Stamm WE, eds. Sexually Cates W, Lemon SM, Stamm WE, eds. Sexually
Transmitted Diseases. 2nd ed. New York: McGraw-Hill, 1990:917-25.

89 Ballard RC, Fehler HG. Chlamydial infections of the eye and genital tract in southern Africa. S Afr Med $\mathcal{F}$ 1986;Suppl:76-9.

90 Ballard RC. The epidemiology and immunopathology of chlamydial infections in southern Africa [dissertation] Johannesburg: University of the Witwatersrand, 1982.

91 Ballard RC, Fehler HG, Piot P. Chlamydial infections of the eye and genital tract in developing societies. In: Oriel D, Ridgway G, Schachter J, Taylor-Robinson D, Ward M, eds. Proceedings of the Sixth International Symposium on Human Chlamydia Infections; 1985 Jump 15-21; Sanderstead, Surrey: Cambridge University June 15-21; Sanders

92 Fehler HG, Mithal Y, Moolla SA, et al. Prevalence of antichlamydial antibody in Johannesburg. A seroepidemiological study. S Afr F Sex Transm Dis 1984;3:111-6.

93 Charlewood GP. Gynaecology in southern Africa. Johannesburg: University of the Witwatersrand Press, 1972.

94 Jennings OGN, Wiswedel K. Prevalence of Chlamydia trachomatis $\operatorname{IgG}$ and $\operatorname{IgA}$ antibody in gynaecology inpatients as determined by serum indirect immunoperoxidase assay. $S$ Afr Med $₹$ 1990;77:234-7.

95 Rubin A. Vaginal discharge in the black pregnant patient. $S$ Afr Med F 1980;57:404-6.

96 Bloch R, Dehaeck CMC. Human papillomavirus and the squamous epithelium of the female genital tract. $S$ Afr Med f 1987:72.557-8.

97 Leiman G. Cervical cancer screening in a Johannesburg family planning centre. S Afr Med f 1976;50:611-5.

98 Markowitz S, Leiman G, Margolius KA. Human papillomavirus and cervical intra-epithelial neoplasia in an
African population. $S$ Afr $\mathcal{F}$ Epidemiol Infect 1986;1:65-9. 99 Learmonth GM, Durcan CM, Beck ID. The changing incidence of cervical intra-epithelial neoplasia. $S A f r$ Med F 1990;77:637-9.

100 Paavonen J, Koutsky LA, Kiviat N. Cervical neoplasia and other STD-related genital and anal neoplasias. In: Holmes KK, Mårdh P-A, Sparling PF, Wiesner PJ, Cates W, Lemon SM, Stamm WE, eds. Sexually Transmitted Diseases. 2nd ed. New York: McGraw-Hill, 1990; 561-92.

101 Lörincz AT. Human papillomavirus detection tests. In: Holmes KK, Mårdh P-A, Sparling PF, Wiesner PJ, Cates W, Lemon SM, Stamm WE, eds. Sexually Transmitted Diseases. 2nd ed. New York: McGraw-Hill, 1990;953-9.

102 Williams A-L, Dehaeck CMC, Soeters R. Typing of human papillomavirus in cervical intraepithelial neoplasia grade 3 biopsies from Cape Town. $₹$ Med Virol 1989; 28:146-9.

103 Cooper K, Herrington CS, Graham AK, Evans MF, McGee JO. In situ HPV genotyping of cervical intraepithelial neoplasia in South Africa and British patients: evidence for putative HPV integration. $f$ Clin Pathol $1991 ; 44: 400-5$.

104 Cooper K, McGee JO. HPV genotypes in cervical neoplasia in South Africa [letter]. $\mathscr{F}$ Clin Pathol 1992;45:90.

105 Cooper K, Herrington CS, Lo ES, Evans MF, McGee JO Integration of human papillomavirus types 16 and 18 in cervical adenocarcinoma. $\mathcal{F}$ Clin Pathol 1992;45:382-4.

106 Johnson JE, Dehaeck CM, Soeters R, Williamson AL Typing and molecular characterization of human papillomaviruses in genital warts from South African women. $\mathfrak{7}$ Med Virol 1991;33:39-42.

107 Department of National Health and Population Development. Syphilis in women attending antenatal clinics, Oct/Nov 1991. Epidemiological Comments 1992;19: 165-70.

108 O'Farrell N, Windsor I, Becker P. HIV-1 infection among heterosexual attenders at a sexually transmitted diseases clinic in Durban. S Afr Med f 1991;80:17-20.

109 Department of National Health and Population Development. First national HIV survey of women attending antenatal clinics, South Africa, Oct/Nov 1990. Epidemiological Comments 1991;18:35-45.

110 Department of National Health and Population Development. Second national HIV survey of women Development. Second national HIV survey of women attending antenatal clinics, South Africa,

111 Department of National Health and Population Development. Third national HIV survey of women attending antenatal clinics, South Africa, Oct/Nov 1992. Epidemiological Comments 1993;20:35-47.

112 Department of National Health and Population Development. Fourth national HIV survey of women attending antenatal clinics, South Africa, Oct/Nov 1993. Epidemiological Comments 1994;21:68-78.

113 Department of National Health and Population Development. Fifth national HIV survey of women Development. Fifth national HIV survey of women Epidemiological Comments 1995;22:90-100.

114 National Institute for Virology. NIV sentinel surveillance. Epidemiological Comments 1995;22:230-1.

115 Schneider $\mathrm{H}$. An assessment of services for the control of sexually transmitted diseases in the PWV province. Johannesburg: University of the Witwatersrand Centre for Health Policy; 1995 Jan. Technical report. 